\title{
Study on Dynamic Model of Initial Emission Rights for Medical Sewage System
}

\author{
Lina Wang1*, Yongqiang Pan², Linjiao Yang1, Yitong Wang ${ }^{3}$, Fulin Li1, Jiaqi Wang1, \\ Shanwei Wang ${ }^{1}$, Na Zuo ${ }^{1}$ \\ ${ }^{1}$ Management School, Liaoning University of Technology, Jinzhou, China \\ ${ }^{2}$ Economy \& Management School, Hainan Normal University, Haikou, China \\ ${ }^{3}$ Media School, Liaoning University, Shenyang, China \\ Email: *lina1976113@126.com
}

How to cite this paper: Wang, L.N., Pan, Y.Q., Yang, L.J., Wang, Y.T., Li, F.L., Wang, J.Q., Wang, S.W. and Zuo, N. (2019) Study on Dynamic Model of Initial Emission Rights for Medical Sewage System. Modeling and Numerical Simulation of Material Science, 9, 29-40.

https://doi.org/10.4236/mnsms.2019.92003

Received: March 15, 2019

Accepted: April 9, 2019

Published: April 12, 2019

Copyright (c) 2019 by author(s) and Scientific Research Publishing Inc. This work is licensed under the Creative Commons Attribution International License (CC BY 4.0).

http://creativecommons.org/licenses/by/4.0/

\begin{abstract}
The chemical oxygen demand (COD) is selected as the index in this paper. The system dynamics method is used to analyze the emission right price of medical sewage, the boundary of the emission right price system is determined, and the system dynamics model of the initial emission right of medical sewage is constructed, in which the system is divided into water resources subsystem, population subsystem, economic subsystem and social subsystem. It is expected to expand the theory of the system modeling of the initial discharge right of medical sewage, and to provide the basis for the relevant decision of the environmental management authorities.
\end{abstract}

\section{Keywords}

System Dynamics, Modeling, Medical Sewage, Initial Emission Rights

\section{Introduction}

Systems Dynamics originated in the United States. "System dynamics is a science in which system science theory and computer simulation are closely combined to study the system feedback structure and behavior." System Dynamics was founded in 1956 by Jay W. Forrester, a professor at the Massachusetts Institute of Science, and was subsequently developed into an independent discipline to understand systemic problems and to solve systemic problems and explore systemic behavior. System dynamics in the early stage of the main study of industrial systems is therefore known as "industrial Dynamics", from the point of view of the system to solve the problem, the consideration of the problem in a system, to determine the boundaries of the system and gradually determine the 
structure of the system, its main idea is that "the structure of the system determines the behavior of the system". System dynamics is a discipline in which system science theory and computer simulation are closely combined to study feedback structure and behavior. The basic theory of system dynamics is system theory and feedback control theory, and the main purpose of system dynamics is to study the structure of a system and study the dynamic behavior of the system from the whole point of view through structural analysis, that is, to study the change of system behavior with time. The purpose of system dynamics is not to seek the optimal solution, but to seek possible ways to improve the behavior of the system. It is to link the existing information through the system structure, with the help of computer software and simulation language for dynamic simulation, the future behavior of the system simulation and description. At the same time, system dynamics is developed on the basis of summing up operational research and adapting to the management needs of modern social systems. It is not based on abstract assumptions, but on the existence of the real world as the premise, do not pursue the "best solution", but from the overall point of view to seek ways and means to improve the behavior of the system. Technically speaking, it is not based on mathematical logic to obtain the answer, but based on the actual observation information of the system to establish a dynamic simulation model, and through computer experiments to obtain a description of the future behavior of the system. Simply put, "system dynamics is a computer simulation method for studying the dynamic behavior of social systems." Specifically, System dynamics includes the following points. 1) System Dynamics studies both life and non-life systems as information feedback systems, and holds that there is a feedback mechanism in each system, which is an important point of view of cybernetics, so system dynamics is based on cybernetics; 2) System dynamics divides the research object into several subsystems, and establish the causality network between the subsystems, based on the whole and the relationship between the whole research, to replace the traditional element view with the whole view; 3) The research method of system dynamics is to establish computer simulation model-flow map and tectonic equation, implement computer simulation test, verify the validity of the model, Provide the basis for the formulation of strategy and decision-making.

System dynamics was introduced to China in the late 1970s, and the research field of domestic system dynamics is extensively related to ecological environmental protection, social security, logistics and supply chain, industrial research, urban transportation, sustainable development, commodity prices and so on. Domestic scholars mainly focus on the application of System dynamics research, through the analysis of system structure, the purpose of determining the system, the construction of causal loop diagram and library flow diagram of the key parameters in the system quantitative analysis, on this basis, an example analysis [1] [2] [3] [4] [5].

In the rational utilization of natural resources, System dynamics provides an 
effective management tool, based on experimental research, combined with the main influencing factors, to give more excellent possible results. System dynamics is widely used in ecology [6], risk assessment [7], economic benefits [8], port development [9], project management [10], strategic management [11], and system dynamics in water resources management is mainly studied in water environment quality, water resources carrying capacity, water resources development and utilization, water resources planning and so on [12] [13] [14]. This paper mainly aims at the model creation of the initial emission right based on the system dynamics method of medical sewage, which is an effective enrichment of the system dynamics and the establishment of the initial emission right model of pollution control sewage.

\section{System Dynamics Modeling Process}

The understanding of the problem by system dynamics is based on the close dependence between the system behavior and the internal mechanism, and obtained through the process of the establishment and operation of the mathematical model, and the relationship between the causes and fruits of the change form is gradually excavated, and the system dynamics is called the structure. Structure refers to a network of interlocking actions or decision-making rules, such as a set of interrelated guidelines, practices, or policies that guide the daily actions and decisions of members of an organization, a set of structures that determine the characteristics of organizational behavior. The main components that make up the system dynamics pattern structure include the following, flow, level, rate, and auxiliary (Forrester, 1961). System dynamics will be represented in the organization in six streams, including order flow, people flow, money flow, equipment flow, material flow, and information flow. These six streams generalize the basic structure contained in the operation of the organization. Level represents things in the real world that can be accumulated or reduced over time, including visible, such as inventory levels, number of people, and invisible, such as the level or pressure of the cognitive load, which represents the state of an environment variable at a certain point in the, and is the source of information in the pattern; the rate represents a certain amount, In terms of the rate of change in unit time, it can simply indicate the increase, decrease or net increase rate, which is the place where information processing and conversion into action; auxiliary variables have three meanings in the pattern, intermediate process of information processing, parameter value, input test function of mode.

Of these, both of the first two meanings can be considered as part of the rate variable. The basic component of the System Dynamics Modeling unit, the information feedback loop structure, is the information feedback loop. The loop is made up of regulatory actions (rates) arising from the current situation, objectives, and the gap between the current situation (level) and the target. The characteristics of the loop behavior are to eliminate the gap between the target and the current situation, such as the adjustment loop of the inventory. In addition 
to the negative ring of the target pursuit, there is a positive feedback loop with self-reinforced, that is, the influence relationship between causality and mutual reinforcement, and the behavior of the system is the process of each other's strength and decline between the loops. In addition to this, however, the structure must include a time delay process, such as the process of the organization, such as production, transportation, transmission, etc., or intangible processes such as the decision-making process, as well as cognitive processes, there are long or short time delays. The modeling process of system dynamics is mainly through observing the interactive operation process of six kinds of streams in the system, and discusses the changes of their level and the various rate behaviors that affect the level in different streams.

The main problem of system dynamics is to analyze the structure of the system, determine the system structure first need to determine the system boundary according to the problem to be studied, analyze the causality between the elements within the system and draw the causal diagram, and then divide the system into several subsystems according to the causality between the elements, and connect the subsystems with the flow chart. After determining the overall structure of the system, the variable properties of each element are set, and the equations between the variables are entered, the model is simulated without errors, and the construction of the System Dynamics model mainly includes the following steps:

1) Determination of system boundaries

To establish the system dynamics model, we should first clarify the problems to be studied, determine the boundary of the system according to the problem, determine the boundary of the system is to consider what factors should be included in the system, and remove those factors that need not be considered. Factors that have an important relationship with the problem under study should be incorporated into the system, while factors that are weak in relation to the research problem are not considered. The system boundary determines the complexity of the system and the size of the system, the system boundary is directly related to the simulation results of the model, if the system boundary is determined unreasonable, the resulting results may not solve the problem, may trigger the wrong decision.

2) Draw a causal diagram

After determining the boundary of the system, the factors of mutual cause and effect within the system are connected with the curve with arrows, that is, the causal chain, and the positive sign or negative sign is marked near the causal chain, indicating that the cause is the same change or the reverse change.

a) Causal Chain

Causality chain is the smallest composition in the System Dynamics model, which represents the causal feedback between the two elements, while " + " indicates the same change between the two, the positive feedback effect between cause and effect is the positive causal chain, and vice versa. 


\section{b) Causality Loop}

The causal loop, also known as the causal feedback loop, consists of a closed loop consisting of two and more of the causal chains that interact in turn. The causal loop has the same positive and negative points as the causal chain, and in the positive causal loop, the change of one variable finally increases the trend of its own change in the same direction, while in the negative causal loop, the change of one variable finally weakens the trend of its own change in the same direction. The polarity of the causal loop is determined by the parity of the number of negative causal chains in the loop. If a loop contains odd numbers of negative causal chains, the polarity of the loop is negative, and if the negative causal chain in the loop is even, the polarity is positive.

3) Identification subsystem

According to the causality between the elements within the system boundary, the system is divided into several subsystems, the structure and feedback mechanism of each subsystem are studied respectively, and the system is finally connected into a whole through the flowchart.

4) Draw the system flow diagram

The system flow diagram is based on the causality diagram, by clarifying the properties of each variable, using the symbol unique to the system dynamics to connect the variables. The flow graph mainly contains level, auxiliary, rate, and constant.

a) Level

Level variables are used to represent the cumulative effect of the system, also known as state variables, reflecting the accumulation of matter, information and energy over time, which is the storage of matter, information and energy.

b) Auxiliary

Auxiliary variables help describe the variables of information feedback, located between level variables and rate variables.

c) Rate

The rate variable, also known as the flow rate variable, is used to represent the change of the level variable.

d) Constant

Constants are quantities that do not change over time during a calculation process.

5) Input variable equation

The relationship between the variables is reflected by mathematical equations and entered into the System Dynamics model.

6) Model parameter design

According to the variable equation in the model, the parameters in the model are defined, and the System Dynamics model generally has several kinds of parameters, such as constant class, conversion coefficient and initial value of state variable, and the parameters are designed reasonably by parameter estimation method. 
7) Model simulation

After testing the model without errors, including the test of model units and variable equations, the use of System dynamics specialized software (such as Stella, Vensim, etc.) to simulate.

8) Model inspection

After the model is preliminarily completed, it is necessary to carry out the preliminary test of the model, that is, unit inspection and model test, and find the errors in the model in time, so that the model can run smoothly.

9) Model simulation debugging and final decision plan determination

After the model is tested without errors, the simulation is carried out, the results of the simulation are analyzed, and then the policy scheme is set up to compare and make the decision.

\section{Construction of Initial Emission Right Pricing Model for Medical Sewage}

\subsection{Determination of Model Subsystem}

In this paper, the chemical oxygen demand (COD) is selected as the index, so the initial discharge right price of medical sewage is equal to the average processing cost of COD. The System Dynamics method is used to analyze the emission right price, determine the boundary of the emission right price system, the medical wastewater is produced because of the domestic water use and the production water in the medical water, the domestic water is determined by the per capita water consumption and the population quantity, the production water is determined by the water consumption per million GDP and GDP, so the system should include Population subsystem and economic subsystem, because of the environmental pollution caused by medical waste water discharge, reduce the social benefits, in order to manage and control the environmental pollution need to invest human, material and financial resources, so the system also contains social subsystems, so the system is divided into water resources subsystem, population subsystem, economic subsystem, social subsystem.

\subsubsection{Water Resources Subsystem}

Water resources subsystem is the core part of the whole system, by water demand to cause drainage demand, water consumption mainly includes two parts of household water consumption and production process, in which the amount of domestic water is determined by the amount of domestic water per capita, and the consumption of production is determined by the value added of GDP. Most of the water is eventually discharged in the form of sewage after use, and more than $80 \%$ per cent of domestic water is discharged in the form of sewage through the sewage discharge coefficient, which links the total amount of water used to the total amount of sewage discharge. The main variable equations of system dynamics in water resources subsystem are:

Total water use $=$ Production water consumption + Domestic water consumption. 
Production of water consumption $=\mathrm{GDP}^{\star}$ Production of water consumption of per dollar of GDP.

Domestic water consumption $=$ amount of domestic water per capita ${ }^{\star}$ Number of total population.

Total sewage discharge $=$ sewage discharge coefficient $*$ Total water use.

Total sewage treatment $=$ Sewage treatment rate ${ }^{\star}$ Total sewage discharge.

Total COD emissions $=$ COD content per ton of sewage ${ }^{\star}$ total sewage discharge.

\subsubsection{Population Subsystem}

Population subsystem is an important part of the system. The change of population number affects the changes of living water demand, thus affecting the sewage discharge, causing the social average cod treatment cost change, that is, affecting the initial discharge right price of sewage. The population subsystem includes the total population number, the population growth value, the population growth rate. The total population number is the state variable indicates the accumulation of the population. The main variable equations in the system are as follows:

Total population $=$ Total population number Initial value + population growth value.

Population growth value $=$ total population number Initial value ${ }^{\star}$ population growth rate.

\subsubsection{Economic Subsystem}

Productive activities promote economic growth while requiring the consumption of water resources and the release to the environment of sewage containing chemical substances produced in the production process. The elements contained in the economic subsystem are GDP (gross domestic product), GDP value added, GDP growth rate, of which GDP is the state variable. The system dynamics equation is:

$$
\begin{aligned}
& \text { GDP }=\text { GDP + GDP value Added. } \\
& \text { GDP value Added }=\text { GDP }{ }^{*} \text { GDP growth rate. }
\end{aligned}
$$

\subsubsection{Social Subsystem}

The social subsystem mainly includes some measures to improve the social benefit, in order to improve the financial resources to control water pollution investment (fixed assets investment, etc.), material resources (drainage pipeline construction, etc.), manpower (sewage treatment personnel, pipe network maintenance personnel) and so on. The variable equations are:

Fixed Assets $=$ Fixed Assets + increase in fixed assets.

Increase in Fixed assets $=$ Fixed Assets ${ }^{*}$ Fixed asset increase rate.

Depreciation of fixed Assets $=$ Fixed Assets ${ }^{\star}$ Depreciation rate of fixed assets.

Pipe network operators $=$ average per person maintenance pipe network length ${ }^{\star}$ Drainage pipe length. 
Total wage $=$ Sewage treatment personnel salary + network personnel salary.

Length of drainage pipe $=$ length of drainage pipe + value added of drainage pipe length.

Length increase of drainage pipe $=$ increase rate of drainage pipe length $*$ Drainage pipe length.

Sewage treatment personnel $=$ Average staffing ratio $*$ Total sewage treatment.

Wages of sewage treatment personnel = Sewage treatment personnel * Average wage of employees.

Pipe network personnel salary $=$ Pipe network operators ${ }^{\star}$ Average employee wages.

\subsection{Model Variable Description}

The model contains 43 variables, of which there are 5 state variables: Fixed assets, average wages of workers, length of drainage pipes, total population, GDP, and 5 rate variables reflecting the speed of change of state variables, 21 auxiliary variables, 12 constants. See Table 1.

\subsection{System Dynamics Variable Equations}

According to the dynamic mixed graph of the initial discharge right pricing system of sewage, the variable equation is established, and the variable equation is used to determine the mathematical relationship between the variables, and 27 variable equations are preliminarily determined:

1) $\mathrm{COD}$ average processing cost $=\mathrm{COD}$ annual total operating cost/COD total annual processing volume.

2) Total annual operating cost of COD = depreciation of Fixed Assets + Total Payroll + annual operating costs + power consumption costs.

3) Depreciation of fixed assets $=$ depreciation rate of fixed assets ${ }^{\star}$ Fixed Assets.

4) Fixed assets $=$ Fixed Assets + increase in fixed assets.

5) Increase in Fixed assets $=$ rate of increase in fixed assets ${ }^{\star}$ Fixed Assets.

6) Total wage $=$ wages of sewage treatment personnel + network personnel wages.

7) Wages of sewage treatment personnel = Sewage treatment personnel ${ }^{*} \mathrm{Av}$ erage wage of employees.

8) Sewage treatment personnel $=$ Average staffing ratio $*$ Total sewage treatment.

9) Network Personnel salary $=$ Pipe network operators ${ }^{*}$ Average employee wages.

10) Pipe network operators $=$ average per person maintenance pipe network length ${ }^{*}$ Drainage pipe length.

11) Drainage Pipe length $=$ drainage pipe length + drainage pipe length increase value.

12) Length of drainage pipe value $=$ Length of drainage pipeline growth rate ${ }^{*}$ length of drainage pipe. 
Table 1. Variable declaration.

\begin{tabular}{|c|c|c|c|c|c|c|c|}
\hline $\begin{array}{l}\text { Serial } \\
\text { number }\end{array}$ & $\begin{array}{l}\text { Variable } \\
\text { name }\end{array}$ & $\begin{array}{l}\text { Variable } \\
\text { type }\end{array}$ & $\begin{array}{l}\text { Variable } \\
\text { unit }\end{array}$ & $\begin{array}{l}\text { Serial } \\
\text { number }\end{array}$ & $\begin{array}{l}\text { Variable } \\
\text { name }\end{array}$ & $\begin{array}{l}\text { Variable } \\
\text { type }\end{array}$ & $\begin{array}{l}\text { Variable } \\
\text { unit }\end{array}$ \\
\hline A & Fixed assets & $\mathrm{L}$ & Ten thousand yuan & 23 & $\begin{array}{l}\text { Salaries of pipe network } \\
\text { personnel }\end{array}$ & A & Ten thousand yuan \\
\hline 2 & $\begin{array}{l}\text { Average wage of } \\
\text { employees }\end{array}$ & $\mathrm{L}$ & Ten thousand yuan & 24 & $\begin{array}{l}\text { Wages of sewage } \\
\text { treatment personnel }\end{array}$ & A & Ten thousand yuan \\
\hline 3 & $\begin{array}{l}\text { Length of drainage } \\
\text { pipe }\end{array}$ & $\mathrm{L}$ & $\mathrm{km}$ & 25 & Total sewage discharge & A & Ten thousand tons \\
\hline 4 & Total population & $\mathrm{L}$ & Ten thousand yuan & 26 & Total sewage treatment & A & Ten thousand tons \\
\hline 5 & GDP & $\mathrm{L}$ & Ten thousand yuan & 27 & Pipe network operators & $\mathrm{A}$ & persons \\
\hline 6 & $\begin{array}{l}\text { Length of drainage } \\
\text { pipeline growth rate }\end{array}$ & $\mathrm{R}$ & $\mathrm{dmnl}$ & 28 & $\begin{array}{l}\text { Sewage treatment } \\
\text { personnel }\end{array}$ & A & persons \\
\hline 7 & $\begin{array}{l}\text { Rate of increase in } \\
\text { fixed assets }\end{array}$ & $\mathrm{R}$ & $\mathrm{dmnl}$ & 29 & $\begin{array}{l}\text { Production water } \\
\text { consumption }\end{array}$ & A & Ten thousand tons \\
\hline 8 & $\begin{array}{l}\text { Average wage growth } \\
\text { rate }\end{array}$ & $\mathrm{R}$ & $\mathrm{dmnl}$ & 30 & $\begin{array}{l}\text { Domestic water } \\
\text { consumption }\end{array}$ & A & Ten thousand tons \\
\hline 9 & $\begin{array}{l}\text { Population growth } \\
\text { rate }\end{array}$ & $\mathrm{R}$ & $\mathrm{dmnl}$ & 31 & Total water usage & A & Ten thousand tons \\
\hline 10 & GDP growth rate & $\mathrm{R}$ & $\mathrm{dmnl}$ & 32 & $\begin{array}{l}\text { Average per person } \\
\text { maintenance pipe } \\
\text { network length }\end{array}$ & $\mathrm{C}$ & $\mathrm{km} /$ per capita \\
\hline 11 & Increase in fixed assets & A & Ten thousand yuan & 33 & $\begin{array}{l}\text { Depreciation rate of fixed } \\
\text { assets }\end{array}$ & C & dmnl \\
\hline 12 & $\begin{array}{l}\text { Drainage pipe length } \\
\text { increase value }\end{array}$ & A & $\mathrm{km}$ & 34 & Average staffing ratio & $\mathrm{C}$ & $\begin{array}{l}\text { persons/ten } \\
\text { thousand tons }\end{array}$ \\
\hline 13 & $\begin{array}{l}\text { Increase in average } \\
\text { wage of employees }\end{array}$ & $\mathrm{A}$ & Ten thousand yuan & 35 & $\begin{array}{l}\text { Average operating cost } \\
\text { per ton }\end{array}$ & $\mathrm{C}$ & yuan/ton \\
\hline 14 & $\begin{array}{l}\text { Population growth } \\
\text { value }\end{array}$ & A & $\begin{array}{l}\text { Ten thousand } \\
\text { persons }\end{array}$ & 36 & $\begin{array}{l}\text { COD content per ton of } \\
\text { sewage }\end{array}$ & $\mathrm{C}$ & dmnl \\
\hline 15 & GDP added value & A & Ten thousand yuan & 37 & $\begin{array}{l}\text { COD Electricity single } \\
\text { consumption }\end{array}$ & $\mathrm{C}$ & $\mathrm{kWh} /$ ton \\
\hline 16 & $\begin{array}{l}\text { Total annual operating } \\
\text { cost of COD }\end{array}$ & $\mathrm{A}$ & Ten thousand yuan & 38 & Average electricity price & $\mathrm{C}$ & yuan/kWh \\
\hline 17 & $\begin{array}{l}\text { COD total annual } \\
\text { processing volume }\end{array}$ & $\mathrm{A}$ & Ten thousand tons & 39 & COD removal rate & $\mathrm{C}$ & $\mathrm{dmnl}$ \\
\hline 18 & $\begin{array}{l}\text { Annual operating } \\
\text { costs }\end{array}$ & A & Ten thousand yuan & 40 & $\begin{array}{l}\text { Amount of domestic } \\
\text { water per capita }\end{array}$ & $\mathrm{C}$ & ton/per capita \\
\hline 19 & $\begin{array}{l}\text { Power consumption } \\
\text { costs }\end{array}$ & A & Ten thousand yuan & 41 & Sewage treatment rate & $\mathrm{C}$ & $\mathrm{dmnl}$ \\
\hline 20 & Total Payroll & A & Ten thousand yuan & 42 & $\begin{array}{l}\text { Sewage discharge } \\
\text { coefficient }\end{array}$ & $\mathrm{C}$ & $\mathrm{dmnl}$ \\
\hline 21 & $\begin{array}{l}\text { Depreciation of fixed } \\
\text { assets }\end{array}$ & A & Ten thousand yuan & 43 & $\begin{array}{l}\text { Water consumption per } \\
\text { dollar GDP }\end{array}$ & $\mathrm{C}$ & ton/yuan \\
\hline 22 & Total COD emissions & A & Ten thousand tons & & & & \\
\hline
\end{tabular}


13) Average wage of employees = average wage of employees + increase in average wages of workers.

14) Increase in average wage of employees $=$ average wage growth rate ${ }^{\star}$ average wage of workers.

15) Annual operating costs $=$ average operating cost per ton ${ }^{\star} \mathrm{COD}$ total annual processing.

16) Power consumption cost $=\mathrm{COD}$ annual treatment total ${ }^{\star} \mathrm{COD}$ Electricity single consumption * Average electricity price.

17) Total annual treatment of COD total $=$ COD removal rate ${ }^{\star}$ COD emissions.

18) Total COD emissions $=$ COD content per ton of sewage ${ }^{\star}$ total sewage discharge.

19) Total water usage $=$ Production water consumption + domestic water consumption.

20) Domestic water consumption $=$ amount of domestic water per capita * Number of total population.

21) Total population $=$ total population + population growth value.

22) Population growth value $=$ population growth rate ${ }^{\star}$ total population.

23) Total sewage treatment $=$ Sewage treatment rate ${ }^{*}$ Total sewage discharge.

24) Total sewage discharge $=$ sewage discharge coefficient $*$ Total water usage.

25) Production water consumption $=$ water consumption per dollar GDP * GDP.

26) $\mathrm{GDP}=\mathrm{GDP}+\mathrm{GDP}$ Added value.

27) GDP value Added = GDP growth rate ${ }^{\star}$ GDP.

\subsection{Model Parameter Design}

The parameters of the model are determined by the variable equation of the model, according to the above variable equations, the parameters in the model are fixed asset depreciation rate, fixed assets increase rate, average staffing ratio, average per person maintenance pipe network length, drainage pipeline length growth rate, average operating cost per ton, average wage growth rate, COD content per ton of sewage, COD electricity consumption, average electricity price, COD removal rate, per capita domestic water consumption, population growth rate, sewage treatment rate, sewage discharge coefficient, GDP water consumption per dollar, GDP growth rate and other parameters. The reasonable design of model parameters not only determines the accuracy of the model but also affects the selection of the final decision scheme, so the model parameter design should be in line with the actual. There are several main methods for estimating model parameters:

1) Collation of income through existing data.

2) Obtaining parameter values for the analysis of variable equations in the model.

3) Reasonable estimation of parameters based on existing relevant system knowledge. 
4) Reasonable selection of parameter values between upper and lower limits according to actual requirements.

5) Analysis of estimation parameters by model reference behavior characteristics.

\section{Conclusion}

In summary, this paper mainly carries on the construction of the initial discharge right pricing model of medical sewage. First determines 4 subsystems of water resources subsystem, social subsystem, economic subsystem and population subsystem, draws the system Dynamics flow chart on the basis of analyzing the correlation relationship between each subsystem, and explains the properties of each variable in the model. Then, according to the relationship between the variables, 27 variable equations are preliminarily determined, and finally the 17 parameters in the model are designed, and the initial emission right pricing model of medical sewage is constructed. It is expected that the system modeling of the initial discharge right of medical sewage should be expanded theoretically, and the basis for the relevant decision of the Environmental Management Authority should be provided.

\section{Supporting Information}

This work was financially supported by the Science and Technology project of Liaoning Science and Technology Bureau of 2017; project (20170540439); the project's name: The pollution controlling model system's construction based on middle-micro scale.

\section{Conflicts of Interest}

The authors declare no conflicts of interest regarding the publication of this paper.

\section{References}

[1] Weber, C. and Vogel, P. (2014) Contingent Certificate Allocation Rules and Incentives for Power Plant Investment and Disinvestment. Journal of Regulatory Economics, 46, 292-317. https://doi.org/10.1007/s11149-014-9257-8

[2] Byun, S.J. and Cho, H. (2013) Forecasting Carbon Futures Volatility Using GARCH Models with Energy Volatilities. Energy Economics, 40, 207-221. https://doi.org/10.1016/j.eneco.2013.06.017

[3] Stranlund, J.K., Murphy, J.J. and Spraggon, J.M. (2014) Price Controls and Banking in Emissions Trading: An Experimental Evaluation. Journal of Environmental Economics \& Management, 68, 71-86. https://doi.org/10.1016/j.jeem.2014.04.002

[4] Xu, L., Deng, S.J. and Thomas, V.M. (2016) Carbon Emission Permit Price Volatility Reduction through Financial Options. Energy Economics, 53, 248-260. https://doi.org/10.1016/j.eneco.2014.06.001

[5] Hintermann, B. (2015) Market Power in Emission Permit Markets: Theory and Evidence from the EU ETS. Environmental \& Resource Economics, 66, 1-24.

[6] Jia, R.A. (2014) Organizational Management System Dynamics. Science Press, Bei- 
jing.

[7] Wang, Q.P. (1994) System Dynamics. Tsinghua University Press, Beijing.

[8] Li, D.Y., Wang, J.G. and Dong, Z.C. (2011) Dynamic Simulation of Algae in Taihu Lake Based on Ecosystem Dynamics Model. Journal of Hydroelectric Power, 3, 124-131.

[9] Tang, W., Lei, X.H. and Li, L.L. (2012) Applicability of System Dynamics in Strategic Risk Assessment and Control. Journal of Tongii University (Natural Science Edition), 40, 645-649.

[10] Li, L.F. and Guo, K.H. (2014) Economic Analysis of Automobile Engine Remanufacturing Based on System Dynamics Model. Journal of Hunan University (Natural Science Edition), 41, 62-66.

[11] Pan, J., Yang, S. and Shen, F.Y. (2012) Model Construction and Simulation of Port City Coupling System Based on System Dynamics-A Case Study of Lianyungang. Theory and Practice of System Engineering, 32, 2439-2446.

[12] Ren, N., He, Y.X., Ma, M.Y. and Wu, J.M. (2014) System Dynamics Model for Performance Prediction of Work Decomposition of Complex Product Projects. Theory and Practice of System Engineering, 34, 3113-3120.

[13] Chen, L.T., Xu, Q.R. and Wu, Z.Y. (2014) Strategic Conception, Innovation Search and Technological Innovation Ability Evolution-Theoretical Modeling and Simulation Research Based on system Dynamics. Theory and Practice of System Engineering, 34, 1705-1719.

[14] Huang, R., Liu, J.M. and Li, L.K. (2012) The Carrying Capacity of Xianyang Water Resources Based on System Dynamics. Journal of Irrigation and Drainage Mechanical Engineering, 30, 57-63. 